\title{
Alternativas metodológicas para licenciaturas em Artes: relato de uma experiência
}

\author{
Methodological alternatives \\ in Art education: \\ report of an experience
}

\author{
Ismael SCHEFFLER*
}

\begin{abstract}
Resumo: No presente texto, desenvolvo um relato da experiência que tenho vivenciado junto a implantação dos cursos de Licenciatura em Artes Visuais e Licenciatura em Música na Universidade Estadual de Ponta Grossa, nos anos de 2004 e 2005. Os cursos, estabelecidos em Eixos Temáticos e Núcleos de Conhecimento, trazem novas possibilidades pedagógicas e novos desafios. No relato, observo com maior atenção a estrutura e o desenvolvimento das atividades de Prática II, que passa pela apreciação artística, pela inserção no contexto escolar através da arte, por atividades em sala de aula e por sua associação à pesquisa em arte, bem como o que foi desenvolvido com relação à pesquisa nos primeiros e segundos anos dos cursos em 2004.
\end{abstract}

Palavras-chave: docência em Artes, formação de professores, pesquisa em Arte

\begin{abstract}
This text narrates the experience of studying in the two courses opened at the State University of Ponta Grossa in 2004 and 2005, namely Visual Arts and Music. The courses, set up into Thematic Centres and Knowledge Groups, bring on new pedagogical possibilities and new challenges. In this report, focus is on the structure and the development of activities in the subject called Practice II, which includes artistic appreciation, its insertion in a school environment through art, classroom activities and its association with art research, in addition to research conducted in the first and second years in 2004 .
\end{abstract}

Key words: Arts education, teacher's education, Art research, report

\footnotetext{
"Mestre em Teatro pela UDESC. Professor colaborador na Universidade Estadual de Ponta Grossa - UEPG. Email: ali_isma@bsi.com.br
}

Olhar de professor, Ponta Grossa, 8(1): 69-78, 2005. 
Em maio de 2004, comecei a trabalhar junto aos cursos de Licenciatura em Artes Visuais e Licenciatura em Música na Universidade Estadual de Ponta Grossa, Paraná. Os cursos, criados em 2003, encontram-se em processo de instalação e apresentam, além dos desafios naturais, um desafio a mais: trabalhar num currículo estabelecido em eixos. O relato apresentado a seguir trata do processo vivenciado e dos desafios encontrados num currículo no qual a prática artística e a pesquisa em arte aparecem como propostas metodológicas de significativa importância na formação de professores de artes.

Num primeiro momento, serão apresentados alguns aspectos gerais sobre o funcionamento das licenciaturas estruturadas em eixos. Após, será feita uma observação mais específica sobre o núcleo temático de Prática. Em seguida, será feito um relato das propostas e realizações em Prática II, nos anos de 2004 e 2005. Por fim, apresentarei a articulação do Eixo Pesquisa em Arte com Prática II, indicando como essa inter-relação tem contribuído para a formação dos futuros professores de artes.

\section{ASPECTOS GERAIS DA ESTRU- TURADOCURRÍCULOEMEIXOS}

A proposta curricular dos cursos de Licenciatura em Artes Visuais e
Licenciatura em Música foi estruturada em cinco grandes eixos temáticos: Pesquisa em Artes, Práticas Artísticas, Atividade Reflexivopedagógicas, Docência em Artes e Estudos Independentes, sendo que a cada eixo correspondem Núcleos de Conhecimentos correspondentes ${ }^{1}$.

A organização em eixos visa ao desenvolvimento de atividades interdisciplinares e ao estabelecimento de maior diálogo entre os conteúdos propostos, numa tentativa de superar a fragmentação ou ao menos amenizar a forma estanque como mais recorrentemente apresentam-se os currículos estabelecidos na forma de disciplinas.

Ao se propor um programa em eixos, diversos desafios surgem, como a necessidade de um planejamento mais integrado e a presença, em vários casos, de mais de um professor ao mesmo tempo dirigindo atividades e expandindo a abordagem dos conteúdos, o que requer, indubitavelmente, a disposição para a experiência de uma nova forma de ensino. Os desafios se colocam ainda no sentido do estabelecimento das parcerias entre professores, uma vez que, para se realizar um planejamento e o desenvolvimento de atividades em pares, trios e até quartetos, é necessário que haja, além de afinidade pessoal, afinidade pedagógica entre profissionais com distin-

${ }^{1}$ Ver Subtil (2004), nessa comunicação, a autora desenvolve considerações sobre cada um dos Eixos que formam o currículo dos cursos de licenciatura em artes da UEPG.

Olhar de professor, Ponta Grossa, 8(1): 69-78, 2005. 
tas formações e de diferentes áreas do conhecimento.

Essa experiência está constituída também a partir da idéia de otimização do tempo dos alunos, conforme preconiza Cabral (1997), provocando um desdobramento das atividades e um maior aproveitamento de trabalhos e discussões realizados.

Além da articulação em Eixos Temáticos, o currículo adota outra articulação, que é a de aproximação das duas licenciaturas. Para a construção de uma visão mais integradora dos futuros professores, são propostas inserções de uma área na outra, bem como do teatro e a dança, contribuindo para a formação de um docente dotado de uma visão e vivência mais abrangente em arte, e que, acima de tudo, procura estabelecer inter-relações. Isso não significa que se visa à formação de professores polivalentes, isto é, professores em diversas áreas artísticas. Antes, trabalha-se na formação de professores de música e de professores de artes visuais capazes de, além de sua área específica, compreenderem de forma um pouco mais profunda outras linguagens artísticas, tornando-se assim mais abertos ao estabelecimento do diálogo. $\mathrm{O}$ que se tem em vista é a ampliação dos conhecimentos artísticos, mas mantendo-se as especificidades de cada licenciatura.

Por isso, vêm sendo trabalhados Eixos Temáticos e Núcleos de Conhecimentos em comum. É o caso de Produções Artísticas que, no primeiro ano, tem desenvolvido atividades dos dois cursos em conjunto, promovendo momentos nos quais se integram teatro, dança, música e artes visuais. Basicamente, todas as atividades são desenvolvidas em conjunto, com exceção de um horário destinado aos núcleos de conhecimento específicos de cada curso, que é o caso de Desenho Artístico, para Licenciatura em Artes Visuais, e de Instrumentalização do Fazer Musical, para Licenciatura em Música.

No presente relato, abordarei dois núcleos desenvolvidos em conjunto pela Licenciatura em Artes Visuais e Licenciatura em Música: Prática e Pesquisa em Arte.

\section{A PRÁTICA NO EIXO DOCÊN- CIAEMARTES}

O Eixo Docência em Artes, que atravessa o curso do primeiro ao quarto ano, está dividido em dois núcleos temáticos: Prática I e II (primeiro e segundo ano) e Estágios Supervisionados (terceiro e quarto ano).

Entendendo-se que a formação do professor de artes se estabelece também a partir de sua vivência artística e de seu envolvimento com a cultura de uma forma mais ampla, a proposta curricular do curso compreende que se faz necessária, desde o primeiro ano, uma carga horária destinada à fruição artística. Não raro, pode-se encontrar nos cursos de licenciatura em artes alunos que não costumam vivenciar eventos culturais, que não 
possuem o hábito de visitar museus e exposições, assistir a espetáculos de teatro, dança ou música. Também é recorrente a existência de alunos que cultivam de forma mais direcionada hábitos artísticos em sua área específica, mantendo uma relação muitas vezes estanque com o universo artístico de forma geral. Apreciar arte para poder ensinar arte torna-se um requisito essencial - e isso sem restrições a uma única linguagem.

É importante considerar também que os próprios Parâmetros Curriculares Nacionais de Artes, entre as orientações didáticas, atribuem ao professor vários papéis, entre eles o de "apreciador de arte", o de "estudioso de arte", o de "inventor de formas de apreciação da arte" (BRASIL, 1997, p. 111). Como assumir esses papéis sem vivenciá-los efetivamente?

O núcleo temático Prática I e II nos dois primeiros anos dos cursos não está restrito à fruição artística, mas a práticas contextuais diversas. Está relacionado à integração dos alunos à realidade cultural, o que significa também um conhecimento do mercado de trabalho de duas áreas correlacionadas: arte e docência. Diz respeito, portanto, aos diversos campos de atuação e ação, onde o artista e o docente em arte estão inseridos, numa dada realidade econômica, e com desafios profissionais que ora se assemelham e ora divergem.

Nesse sentido, existem dois focos centrais relacionados à Prática I e II. No primeiro ano, há uma destinação maior da carga horária e um interesse em aproximar o aluno do contexto artístico local, nacional e internacional; no segundo ano, além de dar continuidade a essas atividades, pretende-se aproximar o aluno de licenciatura ao contexto escolar. Essa aproximação, no entanto, ainda não se qualifica como estágio, mas como uma inserção no universo que transita entre a escola e a arte. Essa inserção é apregoada por Cabral (1997, p. 28), quando defende "uma maior interação universidade-comunidade-escola durante todas as fases da licenciatura...". Tal interação não está restrita apenas ao estágio, uma vez que deve aproximar o aluno da escola, da futura profissão.

\section{AS PROPOSTAS E REALIZA- ÇÕESEM PRÁTICA II}

O relato e reflexão a seguir correspondem ao trabalho realizado em 2004 e 2005 com os segundos anos, no núcleo temático Prática II, do Eixo Docência em Arte.

Dentro desse núcleo existem quatro grupos de atividade:

1) Atividades de assistência, participação e fruição artística

2) Inserção artística no contexto escolar

3) Atividades em sala de aula: reuniões de planejamento, debates, seminários

4) Atividades destinadas à coleta de dados para o Eixo Pesquisa 
3.1 Atividades de Assistência, Participação e Fruição Artística

Dotadas de uma carga horária menor do que no primeiro ano (cerca de 20 horas-aula, ao invés de 50 ), as atividades de assistência e fruição artística em Prática II tornam-se mais direcionadas. Com base na experiência de 2004, assumiu-se como proposta duas vertentes principais: a produção artística para a infância e Bienais de Arte.

Se no primeiro ano a eleição de atividades se dá de forma mais espontânea (os alunos elegem considerável parte das atividades artísticas das quais participam), em Prática II direciona-se o olhar e a discussão para a produção artística feita para a infância, o que leva à percepção através de uma abordagem específica. Quais linguagens artísticas são feitas pensando-se na infância? Que características essa produção possui? $\mathrm{O}$ que a distingue da produção para o adulto? É o caso de produções artísticas nas quais existe uma denominação que pretende distinguir o público por sua faixa etária, como o teatro infantil, a produção da indústria cultural na música, no cinema, na televisão, etc. Olhar a produção artística que se autodenomine para a infância abre a possibilidade de se abordarem temas de discussão relativos a teorias da recepção, universalidade das linguagens artísticas, bem como de auxiliar o futuro docente de arte a ter um olhar crítico em relação ao que se oferece às crianças e aos adolescentes.

Outra ênfase de fruição artística está posta na visita à Bienal de Arte da São Paulo ou a Bienal de Arte do Mercosul, em Porto Alegre. A possibilidade de visitar Bienais põe os alunos em contato com a arte contemporânea nacional e internacional, expandindo as referências e colocando-os em diálogo com um entorno mais amplo. A multiplicidade de manifestações e linguagens visuais presentes nas Bienais e a diversidade de artistas conduzem a uma imersão intensa no contato direto com a arte (e não apenas mediado por recursos de vídeo ou livros) e suscita discussões sobre os caminhos que a arte tem tomado, sua função na sociedade, consolidando a experiência estética de fato. Não obstante a visita à Bienal, a viagem configura-se também como a possibilidade de conhecer outros espaços culturais e exposições, bem como de assistir a espetáculos. Em 2004, a viagem à Bienal de São Paulo rendeu ainda a visita ao Museu da Arte Moderna de São Paulo, à Pinacoteca e à Estação Pinacoteca, à exposição $\mathrm{Cem}$ anos de Moda na OCA, ao espetáculo musical Chicago e à Orquestra Sinfônica de São Paulo. A diversidade de acervos, exposições e audições de artistas nacionais e internacionais e o contato com a arquitetura modernista de Niemeyer demonstram a riqueza de experiências de extrema significância.

A flexibilidade no horário das Práticas é fundamental, já que algumas 
atividades ocorrem em turnos diversos, como espetáculos à noite ou aos domingos, e outras demandam uma duração mais longa, como a visita à Exposição de gravuras de Rembrandt, no Museu Oscar Niemeyer, em Curitiba, ou à própria Bienal de São Paulo.

\subsection{Inserção Artística no Contexto Escolar}

A inserção artística no contexto escolar pretende o estabelecimento de experiências, mediadas pela expressão artística, com crianças e adolescentes dentro das escolas. Assumir a postura de produtores de arte para esse público possibilita um conhecimento ímpar não apenas sobre o funcionamento e organização da arte e da escola, mas especialmente sobre interesses, gostos e recepção dos alunos. A proposta é que se aproveite no $2^{\circ}$ ano as produções artísticas realizadas no $1^{\circ}$ ano pelo eixo Práticas Artísticas e se otimize o trabalho produzido sob orientação dos professores.

Em 2004, os alunos organizaramse em cinco grupos, sendo que a maioria optou por preparar uma nova produção, diferente das realizadas em 2003. Embora se saliente que a proposta não deve residir sobre a idéia de oficina, mas sim de apresentação, um dos grupos optou por desenvolver uma oficina de histórias em quadrinhos, tendo ainda um grupo com espetáculo de teatro de fantoches com sonoplastia ao vivo, outro com uma aula-espetáculo sobre música de diversas nacionalidades, outro com aula-espetáculo sobre Bach, e outro com uma atividade que misturava contação de história e instrumentos de percussão. Todos esses trabalhos foram submetidos à apreciação e discussão em sala, antes de sua aplicação.

Em 2005, os alunos estão articulados em dois grandes grupos: um com espetáculo teatral numa adaptação de Sonhos de uma noite de verão, de Shakespeare, com sonoplastia ao vivo, outro um espetáculo musical baseado em A arca de Noé, de Vinícius de Moraes.

\subsection{Atividades em Sala de Aula}

As atividades em sala também cumprem uma função essencial dentro do núcleo, pois além de serem momentos de encontro e de planejamento, servem para o aproveitamento das atividades de fruição artística, através de discussões e debates em sala de aula e de fundamentação teórica que fornece embasamento argumentativo. Como defende Souza (1997, p. 14), o conhecimento "exige que se instrumentalize o olhar com teorias, estudos e olhares de outras pessoas sobre o objeto".

Tais atividades permitem um complemento às atividades vivenciadas, uma ordenação. Caso contrário, corre-se o risco de se ter um ativismo fragmentado e dissociado, um rol de 
tarefas a serem meramente realizadas, um simples horário de encaixes de atividades diversas.

As atividades destinadas à coleta de dados para o Eixo Pesquisa serão apresentados no item abaixo.

\section{A ARTICULAÇÃO DO EIXO PESQUISA EM ARTE COM A PRÁTICA}

Um dos grupos de atividades que são desenvolvidas em Prática I e II diz respeito à sua articulação com o Eixo Pesquisa em Arte. Para tanto, duas linhas de pesquisa foram estabelecidas, considerando-se a proposta do $1^{\circ}$ ano de inserção artística, denominada "Artistas de Ponta Grossa e região e suas produções", e inserção escolar, no $2^{\circ}$ ano, chamada de "O ensino de artes nas escolas".

O Eixo Pesquisa em Arte também atravessa os quatro anos dos cursos, consistindo em Metodologia da Pesquisa em Artes I, II e III e no Trabalho de Conclusão de Curso ( $4^{\circ}$ ano). No $3^{\circ}$ ano, a pesquisa desenvolve-se novamente junto ao Eixo Docência em Arte, sendo desta vez relacionada ao Estágio Supervisionado.

Além das atividades e conteúdos pertinentes à metodologia científica, foi destinado o segundo semestre como momento de produção de pesquisa. Foi estabelecido para o $2^{\circ}$ ano o tema "O ensino de artes nas escolas estaduais de Ponta Grossa nas turmas de $5^{\text {a }}$ a $8^{\text {a }}$ séries". Sendo esse um dos principais campos de atuação para os professores futuramente formados, acreditamos ser necessário um conhecimento mais amplo desse meio educacional relativo à área artística.

Os alunos trabalharam em grupos de três ou quatro integrantes, com vistas a apoiarem-se no processo da pesquisa, bem como para facilitar a orientação dos trabalhos. Foram desenvolvidos dez projetos ao todo:

1. O uso do desenho na escola.

2. O canto coral na educação escolar.

3. O estudo do movimento cubista dentro da disciplina de artes na $8^{\mathrm{a}}$ série.

4. História em quadrinhos nas aulas de artes.

5. Uso de material industrial reciclável em artes.

6. O ensino instrumental na sala de aula.

7. Influência da mídia no gosto musical do adolescente.

8. O ensino de música a partir das vivências dos alunos.

9. Teatro de bonecos na promoção da socialização de crianças.

10. A situação do ensino de artes nas escolas estaduais de $5^{\text {a }}$ a $8^{\text {a }}$. séries de Ponta Grossa.

Os temas foram definidos pelos próprios alunos, com exceção do tema 10 , onde três alunos se dispuseram a desenvolver uma pesquisa quantitativa aplicando um questionário a 43 professores que ocupam a disciplina de artes e que representaram 54 estabelecimentos estaduais de ensino de 
$5^{\mathrm{a}}$ a $8^{\mathrm{a}}$ séries no município de Ponta Grossa. Os demais grupos realizaram pesquisas qualitativas de caráter exploratório e descritivo.

A pesquisa e a Prática estão obviamente associadas aos demais eixos, incorporando conteúdos como os desenvolvidos em Fundamentos da Ação Docente, dentro do eixo Atividades Reflexivo-pedagógicas ${ }^{2}$.

As monografias realizadas foram retomadas em Metodologia da Pesquisa em Artes III e transformadas em artigos a serem inscritos e apresentados em um evento científico interno e em outro externo em 2005, bem como a serem encaminhados para publicações, possibilitando a discussão e circulação dos temas enfocados, conduzindo os alunos à condição de produtores e divulga-dores de conhecimento. O exercício de releitura de sua própria produção e a possibilidade de re-trabalhar o texto de sua pesquisa para um artigo, tem levado os alunos a um amadurecimento da escrita, a uma reava-liação do conteúdo para a produção de um novo trabalho.

À Prática II corresponde a captação de dados para as pesquisas e também a participação dos alunos em eventos científicos, apresentando as investigações realizadas ao longo do primeiro ano em Metodologia da Pesquisa em Artes I e Prática I.

Em 2004, Metodologia da Pesqui- sa em Artes I seguiu o mesmo modelo de funcionamento: no primeiro semestre, foram trabalhados aspectos relativos à pesquisa científica e, no segundo semestre, foram realizados projetos de pesquisa sobre a linha já mencionada. Os alunos dos primeiros anos organizaram-se em grupos de duas a três pessoas. $\mathrm{O}$ objetivo era o de iniciar na metodologia científica e despertar para questões relativas à realidade mais imediata dos alunos: sua própria cidade e a produção artística nela realizada. $\mathrm{O}$ foco deveria estar não sobre grupos artísticos ou entidades, mas especificamente sobre artistas. Todas os trabalhos envolveram entrevistas e, em alguns casos, também pesquisa documental. Os temas abordados tiveram como enfoque a artistas correlatos, como vistos abaixo:

1. Fotografia-Carlos A. Kugler.

2. Música de banda - maestro Adauto Vieira de Paula.

3. Canto coral - maestrina Margareth Urias.

4. Quadrinhos - Fábio Chibilski.

5. Escultura em ossos e raízes Pedro Ruta.

6. Pintura de ícones religiosos Dom Ruberval Monteiro da Silva.

7. Pêssanky (pintura de ovos) Christiany Chedlovski.

8. Pintura impressionista em telaPlácido Fagundes.

${ }^{2}$ O Eixo Atividades Reflexivo-pedagógicas é constituído pelos núcleos temáticos: Reflexão Artística e Fundamentos da Ação Docente. 
9. Tatuagem - Jéferson Luis Galvão.

10. Música gaúcha - Adelar Bertussi $i^{3}$.

As pesquisas suscitaram questões mais amplas com relação à formação artística, à definição do que seja arte, ao mercado artístico na cidade e aos espaços de exposição e apresentações, propiciando a valorização dos artistas locais e suas produções, como se observa, tão diversificadas.

Especialmente no primeiro ano, a produção científica deparou-se com duas dificuldades que, embora não tenham sido generalizadas, puderam ser constatadas: a dificuldade de escrita, oriunda de um ensino básico falho, e uma visão romântica do artista e da arte, evidenciada nos excessivos adjetivos aplicados e na exaltação da genialidade.

Nesses projetos de estudos, notase que o acadêmico de licenciatura em artes torna-se partícipe de sua formação, estabelecendo escolhas de temas de acordo com seu interesse ou necessidade. Os alunos também não estão restritos a pesquisar unicamente temas de sua área, como é o caso de alunos de licenciatura em música, que pesquisaram sobre escultura; e alunos de artes visuais, sobre teatro de animação.

\section{CONSIDERAÇÕES FINAIS}

Os cursos de Licenciatura em Artes Visuais e Licenciatura em Música da Universidade Estadual de Ponta Grossa ainda estão em processo de implantação. Ano a ano eles têm se tornado realidade e passam por um amadurecimento relativo a seu funcionamento em eixos. Os desafios nessa proposta de trabalho são constantes, tanto em relação aos professores, que se sentem mais cômodos ao permanecer num modelo de trabalho em que seus planejamentos e avaliações são individuais, quanto no que diz respeito aos alunos, que chegam com a expectativa de encontrar disciplinas estanques e percebem que é necessário entender e dialogar dentro de um funcionamento em eixos.

A própria estrutura das atividades e conteúdos que têm sido desenvolvidos precisa ser amadurecida, na busca por alternativas metodológicas que atendam às exigências não apenas no mercado de trabalho local e regional, mas às atuais concepções do perfil do docente de artes. Uma dificuldade, no entanto, que os cursos de licenciatura em artes enfrentam, refere-se ao seu quadro docente, composto em sua maior parte por professores colaboradores. Isso faz com que, por sua temporalidade de con-

\footnotetext{
${ }^{3}$ Embora o músico não resida em Ponta Grossa, possui significativa influência na cidade através dos Centro de Tradições Gaúchas (CTGs) e de alunos de acordeón.
} 
trato e, conseqüentemente, rápida renovação, o funcionamento em eixos seja mais lentamente incorporado e sistematizado.

Por fim, é preciso mencionar que as abordagens da Prática e da pesquisa ao longo dos cursos permanecem em discussão. A busca pelas melhores alternativas que correspondam à relevância almejada para esses trabalhos é constante, para que se possa expandir o olhar, os hábitos, as relações com a investigação em arte e em educação dos futuros professores.

\section{REFERÊNCIAS}

ARAÚJO, R. C. Um estudo sobre o ensino da música nas escolas brasileiras: do século XVI ao século XXI. In: FÓRUM DE PESQUISA CIENTÍFICA EM ARTE DA ESCOLA DE MÚSICA E BELAS ARTES DO PARANÁ, 2., Anais... Curitiba, ArtEMBAP, 2004.

BRASIL. Secretaria de Educação Fundamental. Parâmetros curriculares nacionais: arte. Brasília: MEC/SEF, 1997.

CABRAL, B. A. V. A relação bachareladolicenciatura e a natureza da prática pedagógica em artes. In: SEMINÁRIO SOBRE O ENSINO SUPERIOR DE ARTES E DESIGN NO BRASIL, 1., CEEARTES Comissão de Especialistas de Ensino de Artes e Design. Salvador, 1997.

PIRES, N. A identidade das licenciaturas na área de música: múltiplos olhares sobre a formação do professor. In: ENCONTRO ANUAL DA ABEM - ASSOCIAÇÃO BRASILEIRA DE EDUCAÇÃO
MUSICAL, 12., Anais... Florianópolis, CEARTE/UDESC, 2003.

SOUZA, J. Da formação do profissional em música nos cursos de licenciatura. In: SEMINÁRIO SOBRE O ENSINO SUPERIOR DE ARTES E DESIGN NO BRASIL, 1., CEEARTES Comissão de Especialistas de Ensino de Artes e Design. Salvador, 1997.

SUBTIL, M. J. D. A prática como proposta de integração entre conhecimentos acadêmicos e realidade profissional/cultural para a formação de docentes em artes. In: ENCONTRO ANUAL DA ABEM ASSOCIAÇÃO BRASILEIRA DE EDUCAÇÃO MUSICAL, 12., Anais... Florianópolis, CEARTE/UDESC, 2003.

Licenciatura em música: a construção de uma proposta curricular. In: ENCONTRO ANUAL DA ABEM ASSOCIAÇÃO BRASILEIRA DE EDUCAÇÃO MUSICAL, 13., Anais... Rio de Janeiro, UNIRIO, 2004.

Encaminhado em 28/03/05

Aceito em 21/04/05 